\title{
Patient-centered outcomes used in pediatric focused manual therapies research studies: a secondary data analysis of a systematic review
}

\author{
Beth Carleo ${ }^{1}$, Kristian Anderson ${ }^{2}$, Carol Parnell Prevost ${ }^{1}$ and Katherine A. Pohlman ${ }^{3 *}$ (D)
}

\begin{abstract}
Background: Patient-reported outcome measurements (PROM) are instruments that seek a patient's health or functional status. Inclusion of standardized PROMs in research studies and clinical practice provides a more comprehensive understanding of an intervention from the patient's viewpoint. This secondary analysis identified PROM usage and appropriateness of references for property measurements from clinical trials included in a recent systematic review of pediatric manual therapy.

Methods: All included manuscripts within a recent systematic review had two authors extract PROM and associated property measurement data, including the property measurements supporting citations. Inclusion criteria for the articles were published clinical trials (observational or experimental) of pediatric children receiving manual therapy (any profession) for any condition between 2001-March 2018. For each PROM's associated property measurement, two authors used the COSMIN study design checklist to appraise the quality of the cited study to evaluate the property measurement.

Results: Of the 50 manuscripts included in the systematic review, 20 manuscripts reported the use of 52 PROMs. Of the 52 PROMs assessed, 31 did not make a statement about the instrument's property measurement, 7 PROMs had property measurements stated but not referenced, 4 PROMs stated that the property measurement information was unknown, and 10 had property measurement data with reference(s). These 10 PROMs with referenced property measurements were from 7 unique PROMs: constipation assessment scale, satisfaction visual analog scale (VAS), crying time diary, sleep diary, fear avoidance belief questionnaire (FABQ), pain VAS, and autism treatment evaluation checklist. The assessment of the referenced property measurements found that several property measurement's dimensions had not been assessed and those that had were evaluated were done so with poor or fair standards.

Conclusions: This secondary analysis finds that clinical studies of pediatric manual therapy lack consistent use of PROMs with high quality property measurements. Further research to establish and implement PROMs to be used in future research studies and in clinical settings should become a priority for professions using manual therapy in children.
\end{abstract}

\footnotetext{
* Correspondence: kpohlman@parker.edu

${ }^{3}$ Parker University, 2540 Walnut Hill Lane, Dallas, TX 75229, USA

Full list of author information is available at the end of the article
}

\section{Springer Open}

(c) The Author(s). 2021 Open Access This article is licensed under a Creative Commons Attribution 4.0 International License, which permits use, sharing, adaptation, distribution and reproduction in any medium or format, as long as you give appropriate credit to the original author(s) and the source, provide a link to the Creative Commons licence, and indicate if changes were made. The images or other third party material in this article are included in the article's Creative Commons licence, unless indicated otherwise in a credit line to the material. If material is not included in the article's Creative Commons licence and your intended use is not permitted by statutory regulation or exceeds the permitted use, you will need to obtain permission directly from the copyright holder. To view a copy of this licence, visit http://creativecommons.org/licenses/by/4.0/. 


\section{Introduction}

In recent years, researchers have produced multiple literature reviews on manual therapy use within the pediatric population [1]. Pediatric manual therapy can include spinal manipulative therapy, mobilization, chiropractic/osteopathic manipulative therapy, or cranialsacral therapy [1]. While differences exist between them, all reviews conclude a paucity of evidence for effectiveness, mostly due to methodological flaws within the individual included studies. A consistent methodological flaw was the lack of standardized patient-reported outcome measurements (PROMs) [1].

PROMs are instruments or tools that seek a patient's response to their health, quality of life, or functional status from their health care or treatment [2]. They allow health outcomes to be measured throughout a treatment plan directly from the patient's perspective. Research of chiropractic, a profession that commonly uses manual therapy, frequently uses PROMS focused on musculoskeletal issues in the adult population [3].

There are many obstacles to the adoption of PROMs in clinical practice. Many clinicians lack understanding about the instruments and have concerns that the time it will take to administer PROMs would increase their workload [4]. Additional challenges include achieving higher patient participation rates, especially among older, sicker, and illiterate patients [5]. Despite the understanding of PROM's importance in clinical practice, the routine use of these tools is limited [6].

This secondary data analysis aimed to identify PROMs reported in published clinical trials (observational or experimental) of children receiving manual therapy (any profession) for any condition between 2001-March 2018. For the identified PROMs, two authors extracted property measurement information and evaluated current CONSORT guidelines for reporting property measures [7]. When citations for property measurements were referenced, authors further used COSMIN checklists to evaluate and score the quality of the methods that were conducted to assess the stated property measurement $[8,9]$.

\section{Methods}

\section{Initial systematic review}

Details of the initial systematic review used to identify studies for this research project have been previously published [1]. In brief, the systematic review's inclusion criteria were: full-text reports of randomized controlled trials (excluding feasibility studies without outcome measures) or observational studies with pre and post measurements (case reports were excluded) that included two or more children under the age of 18 treated with any form of manual therapy from any healthcare provider and published in English. This research project was registered on PROSPERO: CRD42016033681 and the initial systematic review [1] was also registered there: CRD42018091835.

\section{Patient-reported outcome measures (PROMs)}

Every included study in the original SR was reviewed by one of the current authors and validated by another author. PROMs used in a study and details stated regarding the PROM's property measurements were extracted. The extracted data were categorized into CONSORT reporting guidelines [7]. Those that did follow CONSORT guidelines were categorized as: "Stated that property measurements were unknown" or "Stated with references". Those that did not follow CONSORT guidelines were categorized as: "None stated," or "Stated, but not referenced". If a reference was cited but then discovered by the authors not to include property measurement evaluations, these manuscripts were changed to "Stated, but not referenced." All information was tabulated and reported.

\section{PROM property measurement assessment}

For unique PROM with property measurements referenced, two authors further evaluated the referenced manuscript. If the same PROM was cited by more than one manuscript, all citations from any of the manuscripts were evaluated for the PROM. First, the referenced manuscript was assessed for which property measurement dimension was being evaluated using the definitions determined by the COSMIN guidelines [8]. Exact property measurement dimensions are: Reliability, Internal Consistency, Measurement Error, Content Validity (including face validity), Criterion Validity, Construct Validity (including Structural Validity, Hypothesis-testing Validity, Cross-cultural Validity), Responsiveness, and Interpretability.

The lead author assessed the property measurement of each article using the respective COSMIN study design quality checklist. The senior author independently evaluated assessments and consensus was reached by discussions between the two authors. Scores for each checklist item were based on a 4-point scale: 'poor', 'fair', 'good', or 'excellent' [9]. Based on the COSMIN recommendation, the overall quality score was determined by taking the lowest rating of any item in the checklist ('worst score counts').

\section{Results}

Patient-reported outcome measures (PROMs)

From the 50 studies that met the Parnell-Prevost [1] review's inclusion criteria, 20 manuscripts (40\%) reported the use of 52 PROMs, with 30 manuscripts (60\%) not using any PROMs. Descriptive details of the 52 PROMs can be found in Supplement \#1. 
Table 1 PROMs used in clinical trials of manual therapy in children and the assessment of their reported property measurements. For more information on the PROMs, please see Supplement \#1

\begin{tabular}{|c|c|}
\hline PROM and Number of Manuscripts & System / Condition being studied \\
\hline \multicolumn{2}{|l|}{ PROM with property measurement stated with references $(n=10)$} \\
\hline Constipation Assessment Scale $(n=1)$ & Constipation and Cerebral Palsy \\
\hline Satisfaction VAS $(n=1)$ & Constipation and Cerebral Palsy \\
\hline Crying time diary $(n=2)$ & Infantile Colic \\
\hline Sleep diary $(n=1)$ & Infantile Colic \\
\hline Fear avoidance back questionnaire $(n=1)$ & Mechanical Low Back Pain \\
\hline Pain VAS $(n=3)$ & Mechanical Low Back Pain, Cuboid Syndrome \\
\hline Autism Treatment Evaluation Checklist $(n=1)$ & Autism \\
\hline \multicolumn{2}{|c|}{ PROM with property measurement stated, but not referenced $(n=7)$} \\
\hline Global rating of change $(n=1)$ & Mechanical Low Back Pain \\
\hline Low back pain severity $(n=1)$ & Low Back Pain \\
\hline Patient specific functional scale $(n=1)$ & Mechanical Low Back Pain \\
\hline Autism Research Institute - secretin outcomes survey $(n=1)$ & Autism \\
\hline Scoliosis Quality of Life Index $(n=1)$ & Scoliosis \\
\hline General Health Question from Quality of Life index $(n=1)$ & Chronic-Tension Type Headaches \\
\hline Pain Intensity $(n=1)$ & Chronic Tension Type Headaches \\
\hline \multicolumn{2}{|l|}{ PROM with property measurement stated as unknown $(n=4)$} \\
\hline Improvement rating $(n=1)$ & Suboptimal Infant Breastfeeding \\
\hline Mother's report of exclusivity of breastfeeding $(n=1)$ & Suboptimal Infant Breastfeeding \\
\hline 5-point subjective rating scale $(n=1)$ & Mechanical Low Back Pain \\
\hline Modified Oswestry disability index $(n=1)$ & Mechanical Low Back Pain \\
\hline \multicolumn{2}{|l|}{ PROM with property measurement not stated $(n=31)$} \\
\hline Defecation frequency $(n=1)$ & Constipation and Cerebral Palsy \\
\hline $24 \mathrm{~h}$ Crying time diary $(n=1)$ & Infantile Colic \\
\hline Crying time diary $(n=1)$ & Infantile Colic \\
\hline Diary for wet night frequency $(n=1)$ & Nocturnal Enuresis \\
\hline Doctor classification system based on parental report $(n=1)$ & Infantile Colic \\
\hline Dysfunctional voiding symptoms $(n=1)$ & Pediatric Dysfunctional Voiding \\
\hline Reported ability to latch and ability to breastfeed $(n=1)$ & Suboptimal Infant Breastfeeding \\
\hline Roland-Morris Disability Questionnaire $(n=1)$ & Low Back Pain \\
\hline Frequency of medication use $(n=1)$ & Low Back Pain \\
\hline Headache diary $(n=1)$ & Headache \\
\hline Headache frequency $(n=1)$ & Chronic tension-type headaches \\
\hline Improvement rating $(n=1)$ & Low Back Pain \\
\hline Numeric Pain Rating Scale $(n=1)$ & Mechanical Low Back Pain \\
\hline Quality of Life $(n=1)$ & Mechanical Low Back Pain \\
\hline Satisfaction rating $(n=1)$ & Low Back Pain \\
\hline Asthma severity and improvement $(n=1)$ & Asthma \\
\hline Behavior scores $(n=1)$ & Otitis Media \\
\hline Parent-reported occurrence $(n=1)$ & Otitis Media \\
\hline Quality of life questionnaire $(n=1)$ & Asthma \\
\hline Carer/Parent quality of life questionnaire $(n=1)$ & Cerebral Palsy \\
\hline Fit and sleep Diaries $(n=1)$ & Cerebral Palsy \\
\hline
\end{tabular}


Table 1 PROMs used in clinical trials of manual therapy in children and the assessment of their reported property measurements. For more information on the PROMs, please see Supplement \#1 (Continued)

\begin{tabular}{ll}
\hline PROM and Number of Manuscripts & System / Condition being studied \\
\hline Parent assessment of child global health and sleep $(n=1)$ & Cerebral Palsy \\
Parent reported changes $(n=1)$ & Cerebral Palsy \\
Pediatric pain profile $(n=1)$ & Cerebral Palsy \\
Quality of life using Child Health Questionnaire $(n=1)$ & Cerebral Palsy \\
VAS to rate spasticity $(n=1)$ & Cerebral Palsy \\
Functional rating index $(n=1)$ & Scoliosis \\
Global Perceived effect scale $(n=1)$ & Upper cervical dysfunction \\
Parent questionnaire $(n=1)$ & Upper cervical dysfunction \\
Vegetative parameters questionnaire $(n=1)$ & Postural asymmetry \\
Visual analog scale for pain $(n=1)$ & Upper cervical dysfunctional \\
\hline
\end{tabular}

As shown in Table 1 , the majority of the 52 PROMs did not make a statement regarding the PROM's property measurements $(n=31,59.6 \%)$. Of the articles that did make a statement on the PROM's property measurements, 7 manuscripts had statements of property measurements existing with no citations; in addition to these, two of the PROMs stated and referenced property measurements, but the references did not include property measurement assessments. A total of 7 PROMs (13.5\%) were categorized as "Stated, but not referenced". In addition, 4 PROMS (7.8\%) described the property measurements as unknown. Only 10 of the 52 PROMs (19.2\%) had references to prompt a property measurement evaluation. These 10 PROMs were from 7 of the 50 initial manuscripts (14.0\%).

\section{Property measurement assessment}

The 10 PROMs identified 7 unique and 3 repeat instruments. As shown in Table 2, at least one property measurement dimension was found for each PROM. Property measurement dimensions not assessed in any of the PROMs include: Measurement Error, HypothesisTesting Validity, and Cross-Cultural Validity.
For the 6 property measurement dimensions assessed with the references, Structural Validity was the most common dimension assessed; however, all 4 assessments receiving 'poor' methodological quality score. Responsiveness was the least referenced property measurement dimension with one PROM (Pain VAS- visual analog scale), and it also received a 'poor' methodological quality score. Among all 16 property measurements assessed, the most common score was 'poor' $(n=11)$. A few received a 'fair' score $(n=4)$, with only Content Validity for pain VAS receiving a 'good' methodological quality score. Checklist evaluations for each PROM and property measurement can be found in Supplement \#2.

\section{Discussion}

This secondary analysis study found a lack of highquality standardized PROMs reported in clinical studies of manual therapies for children. From the 50 studies reviewed, 52 PROMs were found to with 7 unique PROMs having appropriately referenced property measurements. When the methodology for these 7 PROMs' property measurements were evaluated, most were of 'fair' or 'poor' quality. These findings are similar to those

Table 2 Methodological quality assessment of property measurements from PROMs used in research studies of children receiving manual therapy

\begin{tabular}{|c|c|c|c|c|c|c|}
\hline & Reliability & $\begin{array}{l}\text { Internal } \\
\text { Consistency }\end{array}$ & $\begin{array}{l}\text { Content } \\
\text { Validity }\end{array}$ & $\begin{array}{l}\text { Criterion } \\
\text { Validity }\end{array}$ & $\begin{array}{l}\text { Structural } \\
\text { Validity }\end{array}$ & Responsiveness \\
\hline Constipation Assessment Scale $(n=1)[10]$ & POOR & & & & POOR & \\
\hline Satisfaction VAS $(n=1)[10]$ & & & & & POOR & \\
\hline Crying time diary $(n=2)[11,12]$ & & & & POOR $(n=2)$ & & \\
\hline Sleep diary $(n=1)[11]$ & & & & FAIR & & \\
\hline Fear Avoidance Back Questionnaire $(n=1)[13]$ & & POOR & FAIR & & POOR & \\
\hline Pain VAS $(n=3)[13]$ & $\begin{array}{l}\text { FAIR }(n=1) \\
\operatorname{POOR}(n=1)\end{array}$ & & $\begin{array}{l}\operatorname{POOR}(n=1) \\
\operatorname{GOOD}(n=1)\end{array}$ & & $\operatorname{POOR}(n=1)$ & $\operatorname{POOR}(n=1)$ \\
\hline Autism Treatment Evaluation Checklist $(n=1)$ [14] & & POOR & & & & \\
\hline
\end{tabular}


found when the spectrum of outcome measures used in pediatric orthopedic publications were evaluated [15]. Of their 2251 reviewed studies, only $11.5 \%$ used a PROM, with few having appropriate validation. These reviews signify a need to encourage the use of the same scales across multiple trials, which could more efficiently impact treatment strategies for the pediatric population.

Of the 7 PROMs identified with evaluated property measurements, the Autism Treatment Evaluation Checklist [14], Constipation Assessment Scale, and Satisfaction Question with a visual analog scale (VAS) [10] were each used in 1 study only and their property measurements were all found to be developed with 'poor' quality [10]. In a 2015 systematic review of measurement outcomes for children with autism [16] and a 2018 scoping review of constipation [17], neither recommended the use of these tools or any other tool because of the lack of well-developed property measurements. The satisfaction question is commonly measured, especially in musculoskeletal studies; however, it is usually measured with non-standardized, locally-devised tools [18]. All of these outcomes emphasize the need for more standardization of PROMs and their use.

Of the remaining PROMs with evaluated property measurements, both crying time and sleeping duration were collected using a diary format and had Criterion Validity evaluated as either poor or fair, respectively. The diary format is desired as it should reduce recall bias by collecting data 'in the field'. However, diary methods requires a patient or a proxy to self-monitor, with adherence to this protocol shown to be unreliable [19]. With technological advances and better methodological understanding, diaries are still considered viable ways to enrich PROM data, especially for quality of life measures [20].

Studies with evaluated property measurements that looked specifically at musculoskeletal conditions identified 2 PROMs. The Pain VAS was the only PROM to be used in 3 studies. This measure had several property measurements evaluated with a range of quality from 'poor' to 'good'. A Fear Avoidance Belief Questionnaire (FABQ) was also used and found to assess several property measurements with 'fair' or 'poor' quality ratings [13]. A recent commentary by Michaleff et al. highlighted the clinician's challenges to assess pain [21]. They also provide 8 different age-appropriate suggestions for measuring self-report of pain intensity, which included a VAS, along with other validated scales that use color or faces. We recommend the use of one of the 8 scales in the age-appropriate clinical situations.

Importantly, the effort placed on selecting appropriate PROMs needs to include usability in the clinic setting in addition to clinical research. Stinson et al. suggest ease of use and scoring are points in the process where clinical research and clinical practice settings may present different needs [22]. There has been effort dedicated to identifying scales useful to the pediatric population for both settings (e.g., PedIMMPACT, PROMIS). McGrath et al. recommends PedIMMACT for the core outcome domains for both acute and chronic/recurring pediatric pain conditions [23]. PROMIS domains allow for a measure to capture the larger impact of an intervention on a pediatric pain condition [24]. Both measures are limited in use to those who are 5 years of age and older, leaving a void for those younger than this age.

This secondary data analysis is limited to studies included in the initial systematic review. While this limitation allows a more detailed review of the specific content area, these parameters do not allow for a specific review to be developed for this content. The limitation of only reviewing the citations for property measurements included in the studies also limited the potential measurement properties of each PROM; thus, the reporting is certainly incomplete. Another known limitation for all pediatric healthcare and research is the use of proxy-report by parent/caregiver. In the literature, proxy-report of child health has been shown to be contradictory, with both over- and under-estimates reported [25]. Further research is needed to better understand the effect of proxy-reporting of pediatric PROMs.

\section{Conclusion}

This secondary analysis documents the need to develop high-quality PROMs on manual therapy for pediatric populations. Without such PROMs, manual therapy research, as well as practitioners using this therapy, are at a loss for an approach to collect valuable patient data that could best assess patient progress. Further research to establish and implement PROMs to be used in future research studies and in clinical settings should become a priority for professions using manual therapy in children.

\section{Abbreviations \\ CONSORT: Consolidated Standards of Reporting Trials; COSMIN: COnsensus- based Standards for the selection of health Measurement Instruments; PROMIS: Patient Reported Outcomes Measurement Information System; PROMs: Patient Reported Outcome Measures; VAS: Visual Analog Scale}

\section{Supplementary Information}

The online version contains supplementary material available at https://doi. org/10.1186/s41687-021-00305-1

Additional file 1.

Additional file 2 .

Acknowledgements

We would like to acknowledge the content guidance provided by Dr. Lise Hestbaek and Henrik Hein Lauridsen. 


\section{Authors' contributions}

All authors analyzed and interpreted the data. All authors read and approved the final manuscript.

\section{Funding}

Not applicable.

\section{Availability of data and materials}

All data generated or analyzed during this study are included in this published article [and its supplementary information files].

\section{Declarations}

\section{Ethics approval and consent to participate}

Not Applicable.

\section{Consent for publication}

Not Applicable.

\section{Competing interests}

Not applicable

\section{Author details}

'Palmer College of Chiropractic, 4777 City Center Parkway, Port Orange, FL 32129, USA. ${ }^{2}$ Performance Chiropractic, 4350 South Washington Street Suite 100, Grand Forks, ND 58201, USA. ${ }^{3}$ Parker University, 2540 Walnut Hill Lane, Dallas, TX 75229, USA.

Received: 23 November 2020 Accepted: 18 March 2021

Published online: 01 April 2021

\section{References}

1. Parnell Prevost, C., Gleberzon, B., Carleo, B., Anderson, K., Cark, M., \& Pohlman, K. A. (2019). Manual therapy for the pediatric population: A systematic review. BMC Complementary and Alternative Medicine, 19(1), 60. https://doi.org/10.1186/s12906-019-2447-2

2. Weldring, T., \& Smith, S. M. S. (2013). Patient-reported outcomes (PROs) and patient-reported outcome measures (PROMs). Health Services Insights, 6, 61-68.

3. Khorsan, R., Coulter, I. D., Hawk, C., \& Choate, C. G. (2008). Measures in chiropractic research: Choosing patient-based outcome assessments. Journal of Manipulative and Physiological Therapeutics, 31(5), 355-375. https://doi. org/10.1016/j.jmpt.2008.04.007.

4. Fleischmann, M., \& Vaughan, B. (2018). The challenges and opportunities of using patient reported outcome measures (PROMs) in clinical practice. International Journal of Osteopathic Medicine, 28, 56-61. https://doi.org/10.1 016/j.jjosm.2018.03.003.

5. Jahagirdar, D., Kroll, T., Ritchie, K., \& Wyke, S. (2012). Using patient reported outcome measures in health services: A qualitative study on including people with low literacy skills and learning disabilities. BMC Health Services Research, 12(1), 431. https://doi.org/10.1186/1472-6963-12-431.

6. Nelson, E. C., Eftimovska, E., Lind, C., Hager, A., Wasson, J. H., \& Lindblad, S. (2015). Patient reported outcome measures in practice. BMJ., 350, g7818.

7. Moher, D., Hopewell, S., Schulz, K. F., Montori, V., Gøtzsche, P. C., Devereaux, P. J., et al. (2010). CONSORT 2010 explanation and elaboration: Updated guidelines for reporting parallel group randomised trials. BMJ., 340, c869. https://doi.org/10.1136/bmj.c869.

8. Mokkink, L. B., Terwee, C. B. Patrick, D. L, Alonso, J., Stratford, P. W., Knol, D. L., ... de Vet, H. C. W. (2010). The COSMIN study reached international consensus on taxonomy, terminology, and definitions of measurement properties for health-related patient-reported outcomes. Journal of Clinical Epidemiology, 63(7), 737-745. https://doi.org/10.1016/j.jclinepi.2010.02.006.

9. Terwee, C. B., Mokkink, L. B., Knol, D. L., Ostelo, R. W. J. G., Bouter, L. M., \& de Vet, H. C. W. (2012). Rating the methodological quality in systematic reviews of studies on measurement properties: A scoring system for the COSMIN checklist. Quality of Life Research: an International Journal of Quality of Life Aspects of Treatment, Care and Rehabilitation, 21(4), 651-657. https://doi. org/10.1007/s11136-011-9960-1.

10. Tarsuslu, T., Bol, H., Simsek, I. E., Toylan, I. E., \& Cam, S. (2009). The effects of osteopathic treatment on constipation in children with cerebral palsy: A pilot study. Journal of Manipulative and Physiological Therapeutics, 32(8), 648-653. https://doi.org/10.1016/j.jmpt.2009.08.016.

11. Browning, M. M. J. (2008). Comparison of the short-term effects of chiropractic spinal manipulation and occipito-sacral decompression in the treatment of infant colic: A single-blinded, randomized, comparison trial. Clinical Chiropractic, 11(3), 122-129. https://doi.org/10.1016/j.clch.2008.10.003.

12. Miller, J. E., Miller, L., Sulesund, A.-K., \& Yevtushenko, A. (2009). Contribution of chiropractic therapy to resolving suboptimal breastfeeding: A case series of 114 infants. Journal of Manipulative and Physiological Therapeutics, 32(8), 670-674. https://doi.org/10.1016/j.jmpt.2009.08.023.

13. Walston, Z. \& Yake, D. (2016). Lumbar thrust manipulation and exercise for the treatment of mechanical low Back pain in adolescents: A case series. The Journal of Orthopaedic and Sports Physical Therapy, 46(5), 391-398. https://doi.org/10.2519/jospt.2016.6366.

14. Khorshid, K. A., Sweat, R. W., \& Zemba, D. Z. B. (2006). Clinical efficacy of upper cervical versus full spine chiropractic care on children with autism: A randomized clinical trial. Journal of Vertebral Subluxation Research, 9, 1-7.

15. Truong, W. H., Price, M. J., Agarwal, K. N., Suryavanshi, J. R., Somasegar, S., Thompson, M., ... Dodwell, E. R. (2019). Utilization of a wide Array of nonvalidated outcome scales in pediatric Orthopaedic publications: Can't we all measure the same thing? Journal of Pediatric Orthopedics, 39(2), e153-e158. https://doi.org/10.1097/BPO.0000000000001263.

16. McConachie, H., Parr, J. R., Glod, M., Hanratty, J., Livingstone, N., Oono, I. P., ... Williams, K. (2015). Systematic review of tools to measure outcomes for young children with autism spectrum disorder. Health Technology Assessment, 19(41), 1-506. https://doi.org/10.3310/hta19410.

17. Jiang, R., Kelly, M. S., \& Routh, J. C. (2018). Assessment of pediatric bowel and bladder dysfunction: A critical appraisal of the literature. Journal of Pediatric Urology, 14(6), 494-501. https://doi.org/10.1016/j.jpurol.2018.08.010.

18. Fennelly, O., Blake, C., Desmeules, F., Stokes, D., \& Cunningham, C. (2018). Patient-reported outcome measures in advanced musculoskeletal physiotherapy practice: A systematic review. Musculoskeletal Care, 16(1), 188-208. https://doi.org/10.1002/msc.1200.

19. Hufford, M. R., \& Shiffman, S. (2003). Assessment methods for patientreported outcomes. Dis-Manage-Health-Outcomes, 11(2), 77-86. https://doi. org/10.2165/00115677-200311020-00002.

20. Schneider, S., \& Stone, A. A. (2016). Ambulatory and diary methods can facilitate the measurement of patient-reported outcomes. Quality of Life Research: an International Journal of Quality of Life Aspects of Treatment, Care and Rehabilitation, 25(3), 497-506. https:/doi.org/10.1007/s11136-015-1054-z.

21. Michaleff, Z. A., Kamper, S. J., Stinson, J. N., Hestbaek, L., Williams, C. M., Campbell, P., \& Dunn, K. M. (2017). Measuring musculoskeletal pain in infants, children, and adolescents. The Journal of Orthopaedic and Sports Physical Therapy, 47(10), 712-730. https://doi.org/10.2519/jospt.2017.7469.

22. Stinson, J. N., Kavanagh, T., Yamada, J., Gill, N., \& Stevens, B. (2006). Systematic review of the psychometric properties, interpretability and feasibility of self-report pain intensity measures for use in clinical trials in children and adolescents. Pain., 125(1), 143-157. https://doi.org/10.1016/.pa in.2006.05.006.

23. McGrath, P. J., Walco, G. A., Turk, D. C., Dworkin, R. H., Brown, M. T., Davidson, K., et al. (2008). Core outcome domains and measures for pediatric acute and chronic/recurrent pain clinical trials: PedIMMPACT recommendations. The Journal of Pain, 9(9), 771-783. https://doi.org/10.101 6/j.jpain.2008.04.007.

24. DeWalt, D. A., Gross, H. E., Gipson, D. S., Selewski, D. T., DeWitt, E. M., Dampier, C. D., et al. (2015). PROMIS( $\left(^{(}\right)$pediatric self-report scales distinguish subgroups of children within and across six common pediatric chronic health conditions. Quality of Life Research: an International Journal of Quality of Life Aspects of Treatment, Care and Rehabilitation, 24(9), 2195-2208. https://doi.org/10.1007/s11136-015-0953-3.

25. Kamper, S. J., Dissing, K. B., \& Hestbaek, L. (2016). Whose pain is it anyway? Comparability of pain reports from children and their parents. Chiropractic \& Manual Therapies, 24(1), 24. https://doi.org/10.1186/s12998-016-0104-0.

\section{Publisher's Note}

Springer Nature remains neutral with regard to jurisdictional claims in published maps and institutional affiliations. 